IAC-09.B3.4.7

\title{
INTERNATIONAL UTILIZATION AT THE THRESHOLD OF “ASSEMBLY COMPLETE" - SCIENCE RETURNS FROM THE INTERNATIONAL SPACE STATION
}

\author{
Tara M. Ruttley, Deborah L. Harm, Cynthia A. Evans, and Julie A. Robinson \\ International Space Station Payloads Office and ISS Program Science Office \\ NASA Johnson Space Center \\ Houston, Texas 77058 \\ Tara.m.ruttley@nasa.gov, Deborah.harm-1@nasa.gov, Cindy.evans-1@nasa.gov ${ }_{2}$ and Julie.a.robinson@nasa.gov
}

\begin{abstract}
The European Columbus and Japanese Kibo laboratories are now fully operational on the International Space Station (ISS), bringing decades of international planning to fruition. NASA is now completing launch and activation of major research facilities that will be housed in the Destiny U.S. Laboratory, Columbus, and Kibo. These facilities include major physical sciences capabilities for combustion, fluid physics, and materials science, as well as additional multipurpose and supporting infrastructure. Expansion of the laboratory space and expansion to a 6person crew (May 2009), is already leading to significant increases in research throughput even before assembly is completed. International research on the ISS includes exchanges of results, sharing of facilities, collaboration on experiments, and joint publication and communication of accomplishments. Significant and ongoing increases in research activity on ISS have occurred over the past year. Although research results lag behind on-orbit operations by 2-5 years, the surge of early research activities following Space Shuttle return to flight in 2005 is now producing an accompanying surge in scientific publications. Evidence of scientific productivity from early utilization opportunities combined with the current pace of research activity in orbit are both important parts of the evidence base for evaluating the potential future achievements of a complete and active ISS.
\end{abstract}

\section{INTRODUCTION}

$\underline{\text { Historical Perspective }}$

The International Space Station (ISS) has had a continuous presence in space for the last 11 years, and has been undergoing assembly during this time period. ISS represents the most complex and largest vehicle ever occupied in orbit, with partnership including the U.S. National Aeronautics and Space Administration (NASA), Canadian Space Agency (CSA), European Space Agency (ESA), Roscosmos (Russian Space Agency), and Japanese Aerospace Exploration Agency (JAXA). Its importance for human space exploration includes testing of new technologies, systems operational tests, experience gained from long term space flight operations, and knowledge gained from scientific investigations in a microgravity environment. ISS science and technology facilities designed to accommodate a broad range of scientific experiments, from cell biology to human physiology, to materials and physical science studies, tests of technologies and systems support for human exploration will be completed on ISS during its final year of assembly.

In 2008 the addition of ESA's Columbus and JAXA's Kibo scientific modules to the US Destiny and Russian segment modules tripled the ISS laboratory space and research facilities, bringing decades of international planning to fruition. A total of 24 facilities will be on ISS at assembly complete. From September 2000 through April 2009 (Expedition 18), over 400 investigations have been conducted on the 
ISS across all nations, representing over 600 scientists worldwide.

\section{Timetable for ISS Research Results}

We have identified roughly 200 publications through 2008 directly resulting from early NASA research on the ISS. These publications can be found online at www.nasa.gov/iss-science, and in NASA's recent Technical Publication detailing all USOS ISS research through Expedition 15 [1]. The time required to begin to see the results of these investigations varies depending on the field of research. For example, early ISS research results indicate that although human research investigations take longer to complete, the time to publication following completion is relatively short (less than 1 year) [2]. Investigations in human research must be carried out with a sufficient number of crewmembers to achieve adequate statistical power in order to draw appropriate conclusions. However, with the increase of crew size to six in May 2009, a complement of up to 20 human research investigations per expedition is being manifested, which will significantly shorten the time needed to complete human studies.

Physical and biological investigations have a relatively short average completion time (less than 1 year), but may take longer to publish results. This may be due to the number of analyses and models to be completed following return of samples to Earth. Technology development investigations on average take a little more than a year to complete, but can provide publications in less than a year. Likely, this is due to the fact that the design of most of the investigations in this category allows for downlink of data from the ISS with simultaneous data analysis [2].

Throughout the ISS construction period a program of "early utilization" allowed research investigations to take advantage of the facilities or crew already onboard. Examples of early ISS research that has led to benefits to Earth as well as the knowledge gained from ISS experiments should enable future space exploration in preparation for exploring the moon, Mars, and beyond. Here we summarize a few key, early research findings from life and physical science across partners, as well as what is planned for the future as the on-orbit labs are completed in 2010.

\section{LIFE SCIENCE RESULTS TO WATCH}

Biotechnology

An innovative biotechnology investigation that was performed on ISS in 2002 involved a novel method for encapsulation of several different anti-cancer drugs, magnetic triggering particles, and encapsulation of genetically engineered DNA (Microencapsulation Electrostatic Processing System, Principal investigator: D. Morrison, 2002). The experiment system improved on existing microencapsulation technology by using microgravity to modify the fluid mechanics, interfacial behavior, and biological processing methods compared to the way the microcapsules would be formed in gravity (Figure 1) [3, 4]. This ISS research has provided new insight into the best formulations and conditions required to produce microcapsules of different drugs, particularly special capsules containing diagnostic imaging materials and triggered release particles. Additionally, this research has led to the development of a ground-based technology to produce these microcapsules on Earth [5]. Subsequent groundbased studies have used this improved microcapsule technology combined with ultrasound-guided cryosurgery to deliver anti-tumor drugs directly to human prostate tumors that were implanted into mice, and this "focal approach" resulted in a dramatic inhibition of tumor growth [4]. Clinical trials to directly inject microcapsules of anti-tumor drugs into tumor sites are planned at MD Anderson Cancer Center in Houston and the Mayo Cancer Center in Scottsdale, AZ.

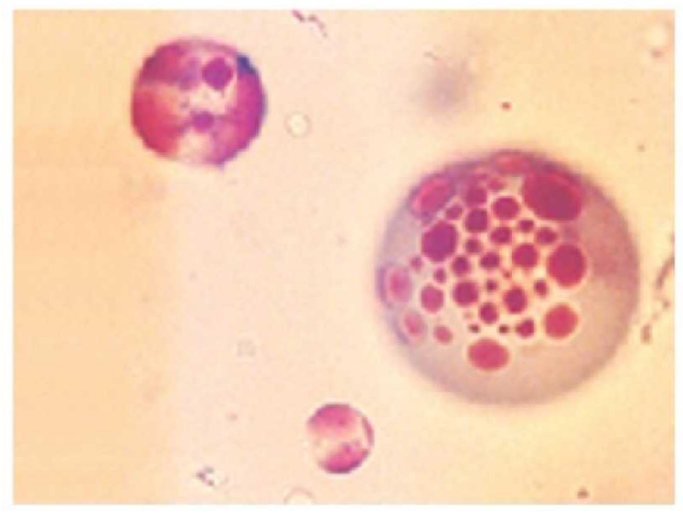

Figure 1. Micro-balloons containing anti-tumor drugs and small amounts of radio-contrast oil during MEPS operations, 2002. Micrograph courtesy of D. Morrison. 
Another life sciences experiment performed on ISS has yielded results that are contributing to advancements in medical technology. The JAXA and Roscosmos-sponsored investigation JAXA-GCF (Japan Aerospace and Exploration Agency Granada Crystallization Facility High Quality Protein Crystallization Project. Principal investigator: H. Tanaka, 2002) was a unique collaboration between several ISS International Partners. The human hematopoietic prostaglandin $\mathrm{D}_{2}$ synthase inhibitor protein (HQL-79) is a candidate treatment in inhibiting the effects of Duchenne's muscular dystrophy. Investigators used the microgravity environment of the ISS to grow larger crystals and more accurately determine the 3dimensional structures of HQL-79 protein crystals (Figure 2). The findings led to the development of a more potent form of the protein, which is important for the development of a novel treatment for Duchenne's muscular dystrophy [6. Russian investigators have collaborated internationally to grow macromolecular crystals on ISS since 2001, including genetically engineered human insulin (deposited into protein data bank in 2008), tuberculosis, and cholera-derived pyrophosphatase. The next generation of Russian-Japanese collaboration in this area is the JAXA High Quality Protein Crystal Growth experiment installed in Kibo in August 2009.

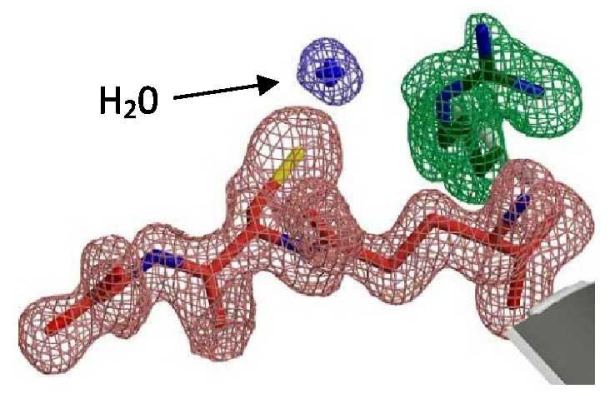

Figure 2. A three-dimensional structure of HQL-79

derived from a crystal grown in space reveals an associated water molecule embedded within the crystal geometry. Understanding this improved structure will aid in the development of nextgeneration medical therapies (figure courtesy of Yoshihiro Urade).

\section{$\underline{\text { Microbial Virulence and Growth }}$}

A human presence in space is inevitably accompanied by the presence of microbes. The extent of changes to microorganisms in response to space flight conditions is not completely understood; however, previous studies have shown that spaceflight causes a dysregulation in the immune system $[7,8,9]$. As astronauts and cosmonauts live for longer periods in a closed environment and use recycled water and air, there is an increase in the potential for negative impacts of microbial contamination upon the health, safety, and performance of crewmembers. Therefore, understanding how the space environment affects microorganisms and their disease-causing potential is critically important for space flight missions and requires further study $[10,11]$. New knowledge on microbial virulence gained in space has significant potential for also benefitting life on Earth.

One of the most exciting microbial results reported from ISS research is the confirmation that common pathogens change and become more virulent during space flight (Figure 3) [12]. The space environment has been shown to induce key changes in microbial cells that play a direct role in infectious disease, including alterations of microbial growth rates, antibiotic resistance, microbial invasion of host tissue, organism virulence (the relative ability of a microbe to cause disease), and genetic changes within the microbe $[12,13]$. The targets identified from each of these microgravity-induced alterations represent an opportunity to develop new and improved therapeutics, including vaccines, as well as biological and pharmaceutical agents aimed specifically at treating the infection.

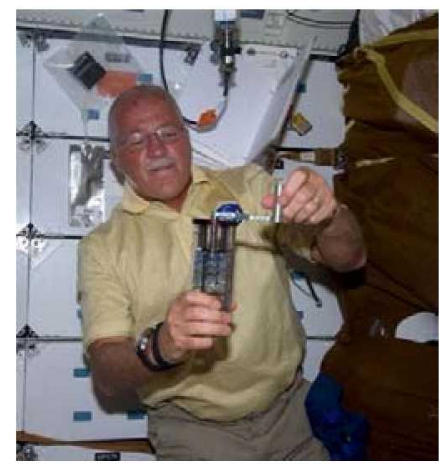

Figure 3. Astronaut John Phillips, STS-119 mission specialist, activates the NLP-Vaccine experiment on the middeck of a shuttle mission to ISS in March 2009. NASA image S119-E-006156. 
For example, Salmonella infection is one of the most common forms of food poisoning in the US. Worldwide, Salmonella diarrhea remains one of the top three causes of infant mortality, so a vaccine has the potential to make dramatic improvements in health for developing countries [14]. Several lines of research on Salmonella bacteria have been conducted since 2006 on space shuttle missions flown to the International Space Station. Collectively, this body of work has shown that the virulence of this organism increases in microgravity. One virulence study performed in microgravity was the Microbe experiment (Effect of Spaceflight on Microbial Gene Expression and Virulence. Principal investigator: C. Nickerson, 2006). Performed in September 2006, it allowed investigators to examine changes in three microbial pathogens: Salmonella typhimurium; Pseudomonas aeruginosa; and, Candida albicans. Initial data from Salmonella typhimurium (a leading cause of human gastroenteritis), showed that 167 transcripts and 73 proteins were expressed differently in flight when compared with ground controls [12]. This apparent response to the microgravity environment included widespread alterations of gene expression, particularly that of the RNA-regulatory binding protein $\mathrm{Hfq}$, that increased disease-causing potential. When using a ground-based model of space flight conditions on Earth, it was possible to reproduce the $\mathrm{Hfq}$ regulation of some of the Salmonella responses that were observed in flight. Hfq is an RNA chaperone that binds to small regulatory RNA and mRNA molecules to facilitate mRNA translational regulation in a cell's stress response [12]. Hfq is also involved in promoting the virulence of several pathogens [15]. Collectively, the spaceflight data suggest that $\mathrm{Hfq}$ is involved in globally regulating the $S$. typhimurium increased virulence associated with spaceflight, and that strategies to target Hfq and related protein regulators could potentially decrease risk of infectious disease on orbit and provide novel treatment therapies for Salmonella infections on Earth.

The 2005 NASA Authorization Act designated a portion of the ISS as a National Laboratory [16]. To fulfill that mandate, NASA instituted the National Lab Pathfinder (NLP) missions, which provide opportunities for non-governmental entities to conduct research and development on ISS by way of each remaining space shuttle flight until the shuttle is retired. In 2008, the NLP-Vaccine experiment, sponsored by AstroGenetix, Inc., began research on its first commercial product, a vaccine for Salmonella, which yielded progressive results targeting a potential vaccine over a succession of four shuttle flights to ISS. The series of experiments used bacterial knock-out gene targets to progressively identify genes associated with microgravity-enhanced bacterial virulence. The genes that have been identified with this increased virulence have become the basis for formulation of a new vaccine against Salmonella typhimurium which is currently in the planning stages for investigational review and approval for future clinical trials.

The NLP-Vaccine bacterial virulence studies, which initially focused on Salmonella, have since been extended to methicillin-resistant Staphylococcus aureus (MRSA) on space shuttle flights to the ISS and during the Hubble Space Telescope Servicing mission between March and May 2009. MRSA is a type of bacteria that causes infections that are resistant to the typical antibiotics used to treat illness caused by this organism. According to the United States Center for Disease Control, it is estimated that MRSA is responsible for more than 94,000 serious infections and 19,000 deaths annually [17]. Preliminary results from the STS-119 (March 2009) experiment showed that growth in space induced phenotypic changes in several microbes, including MRSA, that were not observed in static controls grown on the ground or in rotating clinostats (Hammond and Becker, personal communication). These results are highly valuable for understanding mechanisms used by pathogens to spread disease and also for designing ways to better protect humans in space. With these new insights, similar experiments will continue on the ISS with related sets of pathogens which show promise for potential new development of additional immunetherapeutic products.

These are just two examples of the multiple scientific teams and funding sources in the body of work on microbial growth and virulence in space represents an area of results to watch for in the future.

\section{PHYSICAL SCIENCE RESULTS TO WATCH}

Capillary Flow

The Capillary Flow Experiment (CFE) is a suite of fluid physics experiments whose purpose is to investigate capillary flows and phenomena in low gravity (Capillary Flow Experiment, Principal investigator: M. Weislogel, 2004-2008). The CFE data that is to be obtained will be crucial to future space exploration because they provide a foundation 
for physical models of fluids management in microgravity, including fuel tanks and cryogen storage systems (e.g., water recycling) and materials processing in the liquid state. Under low-gravity conditions, capillary forces can be exploited to control fluid orientation so that such large missioncritical systems perform predictably (Figure 4).

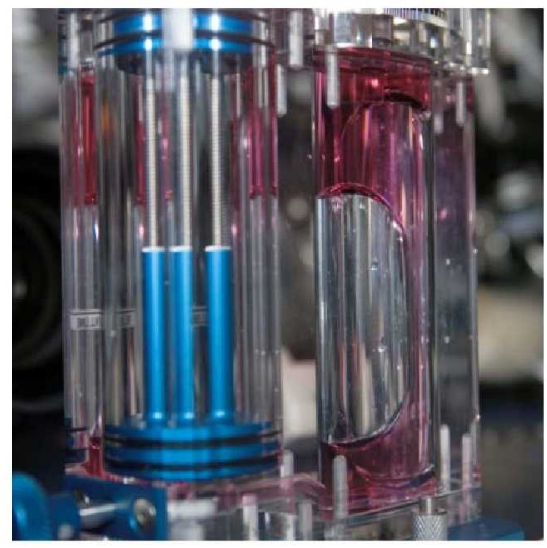

Figure 4. View of Capillary Flow Experiment (CFE) in the U.S. Laboratory/Destiny, 2007. NASA image ISS015E10587.

CFE used distinct experimental apparatus to study three aspects of capillary flow: the contact line, interior corner flow, and vane gap. The contact line (the boundary between the liquid and the solid surface of the container) controls the interface shape, stability, and dynamics of capillary systems in low gravity. Interior corner flow is aimed at practical applications for fluid movement. Interior corners are used in the design of fuel tanks so that the fuel will always flow to the outlet of the tank in the absence of gravity. Experimental results will guide the analysis by providing the necessary boundary conditions as a function of container cross section and fill fraction. The benchmarked theory can then be used to improve propellant management aboard spacecraft. The vane gap focuses on capillary flow when there is a gap between interior corners, such as in the gap formed by an interior vane and tank wall of a large propellant storage tank or the near intersection of vanes in a tank with complex vane network.

CFE tests were operated during ISS Expeditions 9 through 16 (August 2004 - December 2007). Results of the capillary flow investigations are still being published. The contact line measurements have shown the value of the apparatus as a benchmark for computational fluid dynamics models [18]. The numerical approaches used to predict behavior of fluids in microgravity can be improved by evaluating their boundary conditions determined by fluid wetting container geometries. The results have important implications for design of fuel tanks and other fluid systems for use in orbit $[19,20,21,22$, 23].

\section{Materials Testing and Technology Development}

One of the most prolific series of investigations on the ISS was also the first externally-mounted experiment on ISS, the Materials International Space Station Experiment (MISSE, Principal Investigators: W. Kinard and R. Walters, 2001 - ongoing). Researchers from the private and public sector prepared a wide range of samples for MISSE-1 and 2 , which were test beds for more than 400 materials and coatings samples, testing their survivability under the corrosive effects of the space environment, including micrometeorite and orbital debris (MMOD) strikes; atomic oxygen (AO) attack; intense ultraviolet radiation from the sun; and, extreme temperature swings. Beginning with the MISSE-1 and MISSE-2 deployment on the ISS in 2001, and subsequent MISSE-3, MISSE-4, MISSE-5, and MISSE-6 investigations through September 2009, the experiments have provided space-validated results for ground-based experiments, such as the durability of materials to withstand $\mathrm{AO}$ erosion [24]. Because AO erosion is the primary weathering force on spacecraft materials, and true space environmental conditions are difficult to replicate on Earth, MISSE provides a valuable test platform that enables methods for correlating and extrapolating ground results. Each MISSE investigation has yielded results that have subsequently led to increasingly complex follow-on MISEE investigations that allow testing of new materials and new technologies.

Thousands of materials samples have been tested to date through the MISSE series of experiments (Figure 5). MISSE results have been used to understand and calibrate how materials that are already in use on spacecraft degrade in the space environment (for example, polymers used for insulation, and solar array materials) and predict the durability of new materials (e.g., the solar cell materials that are planned for the Commercial Orbital Transportation System) [25]. The US Department of Defense (DOD) sponsored a MISSE-5 experiment that was designed to characterize the durability and 
electrical output of 39 advanced solar cell samples that could be used on future space exploration vehicles. Understanding the performance of these materials will promote the effort to develop future space power systems that could be better protected against degradation from the space environment $[26$, 27].

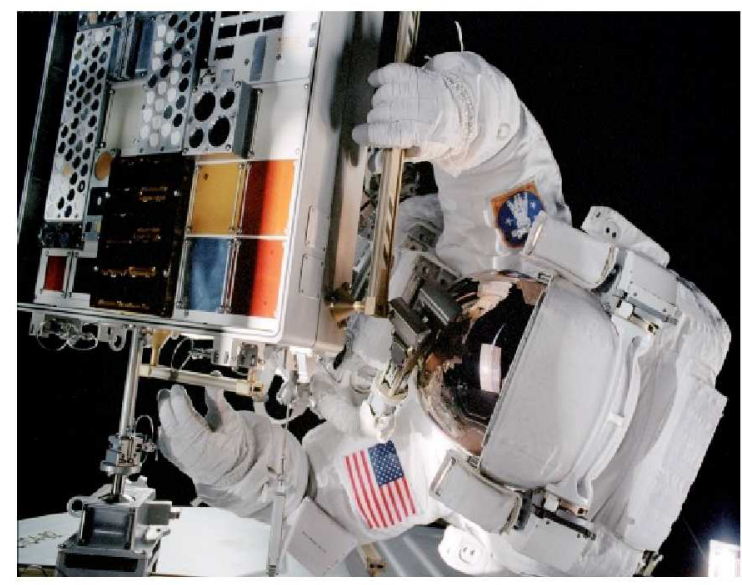

Figure 5. Astronaut Patrick G. Forrester, during the second STS-105 extravehicular activity, prepares to work with the Materials International Space Station Experiment 1 and 2 (MISSE-1 and 2) in August 2001. NASA Image: STS105-346-007

MISSE samples that are currently being tested on the ISS include materials that are part of the design of the new Orion vehicle [24]. In addition to several recent and upcoming publications, MISSE investigators have devised methods for measuring and predicting AO erosion yields, and have assembled data that will provide important reference for designers, developers, and builders of future spacecraft and instruments $[24,25]$.

Additional Earth-based benefits of the MISSE series results include the use of $\mathrm{AO}$ to remove organic content from surfaces for diverse applications. For example, methods using $\mathrm{AO}$ techniques have been developed to restore valuable artwork, and to remove bacteria contaminants from surgical implants [28]. A recent patent was awarded to etch the surface of the optical fibers that are used for blood analyses to increase the surface area and enable rapid assessment of blood glucose levels [29]. The MISSE team has also spearheaded innovative collaborations among industry, academia, NASA, and the DOD. The MISSE series on ISS continues later this year with the arrival of MISSE-7A and 7B with a new batch of experiments and materials aboard STS-129, targeted for launch in November 2009.

\section{FUTURE ISS UTILIZATION}

Although constraints on up-mass to orbit and crew availability on ISS have limited the scope of research during the early utilization period, the science return to date provides strong evidence for the high potential of ISS science return after assembly is complete. As this unprecedented international orbiting research platform is rapidly approaching completion, it will continue to be used to conduct multidisciplinary research and technology development for the benefit of humankind, but with a much higher science throughput than during the early utilization period. From a U.S. perspective, future use of the International Space Station has been expanded through the designation of the ISS US segment as a National Lab by Congress in the NASA Authorization Act of 2005 [16]. This opens up the ISS for use by other government agencies and commercial interests to perform scientific and engineering studies that further their objectives. The ISS has and will continue to be a model for international cooperation and collaboration in space.

The world's space agencies share common goals for ISS utilization. While the various international partners may emphasize different aspects of research to achieve their goals in the use of ISS, they are unified in several important overarching goals. All partners recognize the importance of leveraging the ISS as an education platform to encourage and motivate today's youth to pursue careers in math, science, and engineering. The ISS partners also share the goal of advancing knowledge in the areas of human physiology, biology, material and physical sciences, and translating that knowledge to health, socioeconomic, and environmental benefits on Earth. We may not yet know what will be the most important knowledge gained from the ISS, but we do know that there are some amazing discoveries on the way. Experiments such as those identified in this paper are just a few success stories to watch expand from the unique international laboratory that is the International Space Station. 


\section{REFERENCES}

[1] NASA. June 2009.International Space Station science research accomplishments during the assembly years: An analysis of results from 20002008. NASA/TP-2009-213146-Revision A.

[2] Tate J, Thumm T, Weiss R, Robinson J. 2007. Research on the International Space Station: Understanding Future Potential From Current Accomplishments. 58th International Astronautical Congress. IAC-07-B3.4.07.

[3] Le Pivert P, Morrison D, Haddad R, Renard M, Aller A, Titus K, Doulat J. 2009. Percutaneous Tumor Ablation: Microencapsulated Echo-guided Interstitial Chemotherapy Combined with Cryosurgery Increases Necrosis in Prostate Cancer. Technology in Cancer Research and Treatment. 8(3): 207-216.

[4] Le Pivert P, Haddad R, Aller A, Titus K, Doulat J, Renard M, Morrison D. 2004. Ultrasound Guided, Combined Cryoablation and Microencapsulated 5Fluorouracil, Inhibits Growth of Human Prostate Tumors in Xenogenic Mouse Model Assessed by Fluorescence Imaging. Technology in Cancer Research and Treatment. 3(2):135-42.

[5] Morrison, D. Microparticle Analysis System and Method, U.S. Patent No. 7,295,309, November 13, 2007.

[6] Okinaga T, Mohri I, Fujimura H, Imai K, Ono J, Urade Y, Taniike M. 2002. Induction of Hematopoietic Prostaglandin D Synthase in Hyalinated Necrotic Muscle Fibers: Its Implication in Grouped Necrosis. Acta Neuropathol. 104:377-384.

[7] Sonnenfeld G, Shearer W. 2002. Immune function during space flight. Nutrition. 18: 899-903.

[8] Pierson D, Stowe R, Phillips T, Lugg D, Mehta S. 2005. Epstein-Barr Virus Shedding by Astronauts During Spaceflight. Brain, Behavior, and Immunity. 19:235-242.

[9] Crucian B, Stowe R, Mehta S, Yetman D, Leal M, Quiriarte H, Pierson D, Sams, C. 2009. Immune Status, Latent viral Reactivation, and Stress During Long-duration Head-down Bed Rest. Aviat Space Environ Med. 80(5, Suppl.):A37 - 44.

[10] Nickerson C, Ott C, Mister S, Morrow B, BurnsKeliher L, Pierson D. 2000. Microgravity as a Novel
Environmental Signal Affecting Salmonella enterica Serovar Typhimurium Virulence. Infection and Immunity. 68(6):3147-3152.

[11] Nickerson CA, Ott CM, Wilson JW, Ramamurthy R, Pierson DL. 2004. Microbial Responses to Microgravity and Other Low-Shear Environments. Microbiology and Molecular Biology Reviews. 68(2):345-361.

[12] Wilson J, Ott C, Hoener zu Bentrup K, Ramamurthy R, Quick L, Porwollik S, Cheng P, McClelland M, Tsaprailise G, Radabaugh T, Hunt A, Fernandez D, Richter E, Shah M, Kilcoyne M, Joshi L, Nelman-Gonzalez M, Hing S, Parra M, Dumars P, Norwood K, Bober R, Devich J, Ruggles A, Goulart C, Rupert M, Stodieck L, Stafford P, Catella L, Schurr M, Buchanan K, Morici L, McCracken J, Allen P, Baker-Coleman C, Hammond T, Vogel J, Nelson R, Pierson D, Stefanyshyn-Piper HM, Nickerson C. 2007. Space Flight Alters Bacterial Gene Expression and Virulence and Reveals a Role for Global Regulator Hfq. Proceedings of the National Academy of Sciences of the United States of America. 104(41):16299-16304.

[13] Wilson J, Ott C, Quick L , Davis R, Hoener zu Bentrup K, Crabbe A , Richter E, Sarker S, Barrila J, Porwollik S, Cheng P, McClelland M, Tsaprailis G, Radabaugh T, Hunt A, Shah M, Nelman-Gonzalez M, Hing S, Parra M, Dumars P, Norwood K, Bober R, Devich J, Ruggles A, CdeBaca A, Narayan S, Benjamin J, Goulart C, Rupert M, Catella L, Schurr MJ, Buchanan K, Morici L, McCracken J, Porter M, Pierson D, Smith S, Mergeay M, Leys N, Stefanyshyn-Piper HM, Gorie D, Nickerson C. 2008. Media Ion Composition Controls Regulatory and Virulence Response of Salmonella in Spaceflight. PLoS One. 3(12).

[14] Voetsch A, Van Gilder T, Angulo F, Farley M, Shallow S, Marcus R, Cieslak P, Deneen V, Tauxe R. 2004. FoodNet Estimate of the Burden of Illness caused by Nontyphoidal Salmonella Infections in the United States. Clinical Infectious Diseases. 38:S127S134.

[15] Sittka A, Pfeiffer V, Tedin K, Vogel J. 2007. The RNA chaperone Hfq is essential for the virulence of Salmonella typhimurium. Molecular Microbiology 63:193-217.

[16] Congressional Budget Office H.R. 3070. NASA Authorization Act of 2005. Available online at $\mathrm{http}: / / \mathrm{www} . c b o . g o v /$ doc.cfm? index $=6584$. 
[17] Klevens R, Morrison $M$, Nadle J, Petit S, Gershman K, Ray S, Harrison L, Lynfield R, Dumyati G, Townes J, Craig A, Zell E, Fosheim G, McDougal L, Carey R, Fridkin S. 2007. Invasive Methicillin-Resistant Staphylococcus aureus Infections in the United States. Journal of the American Medical Association. 298(15):1763-1771.

[18] Jenson R, Weislogel M, Chen Y, Tavan N, and Bunnell C. 2009. The Capillary Flow Experiments Aboard the International Space Station: Increments 9-15, 8/2004-12/2007. Tech. Rep. NASA/CR-2009215586 , in preparation.

[19] Jenson R, Weislogel M, Klatte J, and Dreyer M. 2009. Dynamic Interface and Contact Line Experiments Aboard ISS: a Database for Spacecraft Numerical Benchmarks. $A I A A J$., in final Preparation.

[20] Weislogel, M., Thomas, E., and Graf, J. August 2008a. A Novel Device Addressing Design Challenges for Passive Fluid Phase Separations Aboard Spacecraft. J. Microgravity Sci. Technol. p. 1-12.

[21] Weislogel M, Chen Y, Bolleddula D. A Better Non-Dimensionalization Scheme for Slender Flows: The Laplacian Operator Scaling Method. 2008b. Phys. Fluids, 20(9): 1-7.

[22] Weislogel $M$, Jenson $R$, Chen $Y$, Collicott S, Klatte J, Dreyer M. 2009; in press. The Capillary Flow Experiments Aboard the International Space Station: Status. Acta Astronautica.

[23] Klatte J, Haake D, Weislogol M, Dreyer M. 2008. A Fast Numerical Procedure for Steady Capillary Flow in Open Channels. Acta Mech. 201:269-276.

[24] de Groh K, Banks B, Dever J, Jaworske D, Miller S, Sechkar E, Panko S. 2008. NASA Glenn Research Center's Materials International Space Station Experiments (MISSE 1-7). NASA TM-2008215482.

[25] de Groh K, Banks B, McCarthy C, Rucker R, Roberts L, Berger L. 2006. MISSE PEACE Polymers Atomic Oxygen Erosion Results. NASA TM-2006214482.

[26] Walters R, Garner J, Lam S, Vasquez J, Braun W, Ruth R, Warner J, Lorentzen J, Messenger S,
CDR Bruninga $R$, Jenkins $P$, Flatico J, Wilt $D$, Piszczor M, Greer L, Krasowski M. Materials on the International Space Station Experiment-5, Forward Technology Solar Cell Experiment: First On-Orbit Data, Conference Record of the 2006 IEEE $4^{\text {th }}$ World Conference on Photovoltaic Energy Conversion, May 2006; Volume 2, pp. 1951-1954.

[27] Walters R, Garner J, Lam S, Vazquez J, Braun W, Ruth R, Warne J, Lorentzen J, Messenger S, CDR Bruninga R, Jenkins $P$, Flatico J, Wilt D, Piszczor M, Greer L, Krasowski M. Forward Technology Solar Cell Experiment First On-Orbit Data, $19^{\text {th }}$ Space Photovoltaic Research and Technology Conference, (2007) NASA CP-2007-214494, 79-94.

[28] Stambler A, Inoshita K, Roberts L, Barbagallo C, de Groh K, Banks B. Ground-Laboratory to InSpace Atomic Oxygen Correlation for the PEACE Polymers, $9^{\text {th }}$ International Conference on "Protection of Materials and Structures from Space Environment," May 20-23, 2008, Toronto, Canada.

[29] Banks B. 2007. Energetic Atomic and Ionic Oxygen Textured Optical Surfaces for Blood Glucose Monitoring. US Patent No 7,305,154. 